\title{
Monostotic Fibrous Dysplasia of the Lumbar Spine with Pathologic Fracture: A Case Report with Treatment and Follow-up
}

Habibollahzadeh P, Sadat M, Mehrpour SR, Hassanmirzaei B* and Mozafari M

Teheran University of Medical Siences, Tehran, Iran

\begin{abstract}
Objective: To discuss our experience beside others in order to get a better view about these cases and their management.

Summary of background data: Fibrous dysplasia (FD) is a developmental abnormality of the bone and it represents about $7 \%$ of the benign bone tumors; hence vertebral involvement is reported in only $2.5 \%$ of all cases. An agreed method of treatment has not been established yet.

Methods: A 33 year old woman with a history of non specific chronic low back pain for more than 3 years, presented with sudden onset of an acute and severe low back pain with normal examination except for a local tenderness on lumbar vertebrae. Encountering a patient presenting red flags, spine radiography, bone scan, spinal CT scan and MRI was done and the patient underwent CT-guided biopsy afterward. When the diagnosis of fibrous dysplasia was done, she was treated with curettage and fixation with cage, screw and allograft insertion.
\end{abstract}

Results: The patient was followed for one year investigating spine stability, neurological deficit or any other symptoms which represent a one year good follow up outcome.

Conclusion: Based on our experience, here we recommend curettage, cage fixation and allograft insertion in cases of monostotic fibrous dysplasia of the spine when pain, fracture or instability exists.

\section{Keywords: Lumbar monostotic fibrous dysplasia; Curettage;} Allograft

\section{Introduction}

Fibrous dysplasia (FD) is a developmental abnormality of the bone and it represents about seven percentages of the benign bone tumors.This tumor is characterized by replacement of normal bone and its marrow by fibrous-osseous tissue. This will result in decrease of bone strength, deformity. It consists of two types: It may be limited to a single bone (monostotic FD) or disseminated (polyostotic FD) [1-5]. Various types of the disease are described in combination with fibrous dysplasia such as McCune-Albright syndrome [6]. The natural course of the disorder is unpredictable. FD can involve any bone but the vertebral involvement is reported only in $2.5 \%$ of all the case. Monostotic involvement of spine is very rare and only fifty-four cases have been reported yet $[7,8]$. Since the symptoms overlap with the other pathologic conditions, diagnosing fibrous dysplasia in spine can be a big challenge.

Despite the absence of any established approach based on the management of this condition, many authors advocate deformity or fractures, which have lead to instability need surgical treatment with curettage and allograft replacement. Here we introduce and explain therapeutic management of a pathologic fracture of the lumbar spine (L3) vertebra caused by monostotic FD.

\section{Case Presentation}

A 33 year old woman with a history of non specific chronic low back pain for more than 3 years, presented with sudden onset of an acute low back pain without any radiculopathy which interferes with sleeping. Examination revealed no neurological findings, no skin lesions or any evident of the deformity. There was no local mass but a local tenderness on the lumbar spinous processes was present. Encountering a patient presenting with the red flags, spine radiography was taken, which showed a destructive lesion of the 3rd lumbar vertebra in both Anteropostero and Lateral views. According to the destruction of the vertebra and possibility of bone tumors, bone scan, spinal CT scan and MRI was done (Figures 1-3) and the patient underwent CT-guided biopsy afterward. Pathology report proposed fibrous dysplasia and a surgical plan was set.

Using the anterior retroperitoneal approach, the L3 vertebral body was identified and checked with C-Arm. Then the tumor in the vertebral body was removed and the curettage was completed using the

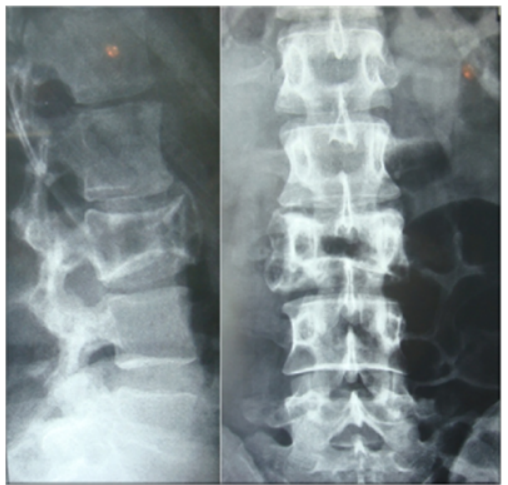

Figure1: Supplemental Digital Content 1. TIF The Plain X-Ray of the patient before surgery (AP and Lateral views) showing destructive lesion in the body of L3.

*Corresponding author: Bahar Hassanmirzaei, Orthopedics Department, Teheran University of Medical Siences, Shariati hospital , Jallal-al-ahmad street, Tehran Iran; Tel: +98-912-2772485; Fax: +98-21-88220055; E-mail: bahariane@yahoo.com

Received February 13, 2013; Accepted July 29, 2013; Published July 31, 2013

Citation: Habibollahzadeh P, Sadat M, Mehrpour SR, Hassanmirzaei B, Mozafari M (2013) Monostotic Fibrous Dysplasia of the Lumbar Spine with Pathologic Fracture: A Case Report with Treatment and Follow-up. J Spine 2: 140. doi:10.4172/21657939.1000140

Copyright: (c) 2013 Habibollahzadeh P, et al. This is an open-access article distributed under the terms of the Creative Commons Attribution License, which permits unrestricted use, distribution, and reproduction in any medium, provided the original author and source are credited. 
Citation: Habibollahzadeh P, Sadat M, Mehrpour SR, Hassanmirzaei B, Mozafari M (2013) Monostotic Fibrous Dysplasia of the Lumbar Spine with Pathologic Fracture: A Case Report with Treatment and Follow-up. J Spine 2: 140. doi:10.4172/2165-7939.1000140

Page 2 of 3

power Burr. Subsequently the vertebral body was reconstructed using an expandable cage and allograft (Figure 4). To enhance the stability of the construct we put one screw above and below the L3 and fixed it with a rod and patient's life quality and medical follow up for one year revealed good outcomes.

\section{Discussion}

Fibrous dysplasia is not an uncommon disease of the bone with a prevalence of $7 \%$ of all benign bone tumors. Depending on the number of bones affected, it is divided into two subtypes: monostotic and polyostotic. The monostotic variant has a significantly higher incidence

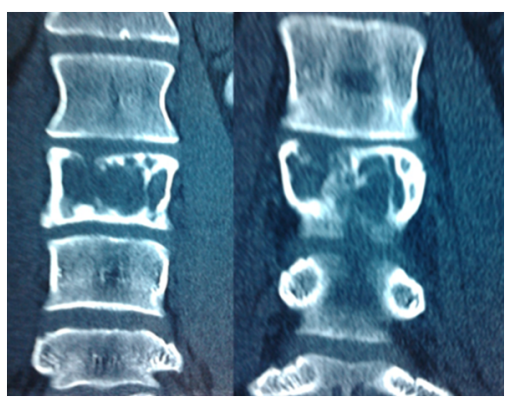

Figure 2: Supplemental Digital Content 2.TIF. The CT-Scan of the patient before surgery showing destructive lesion in body of L3.

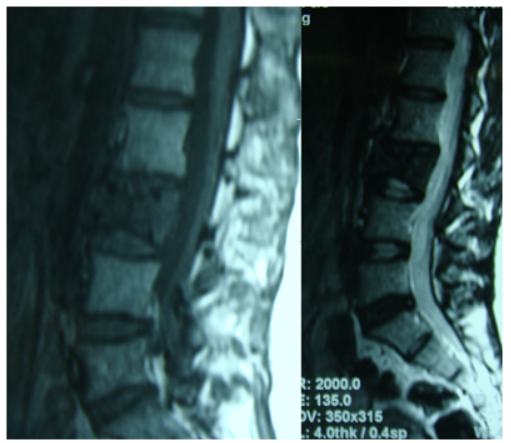

Figure 3: Supplemental Digital Content 3. TIF. The MRI of the patient before surgery (T1) (T2) revealing destructive lesion in L3.

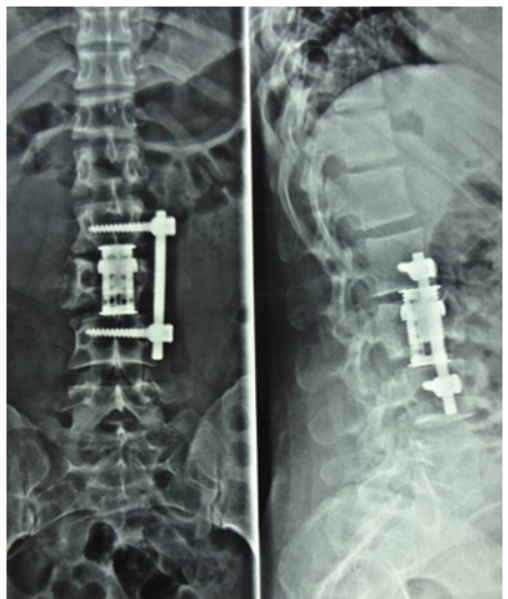

Figure 4: Supplemental Digital Content 4. TIF. The post-operative X-Ray of the patient which. than the polyostotic form ( $70 \%$ and $30 \%$ respectively). However the polyostotic form is frequently seen in association with other pathologic situations such as McCune - Albright or Mazabraud syndromes $[1,2,6]$

While any bone can be affected by the fibrous dysplasia, the most common sites of the disease are the femur, tibia, ribs, skull, facial bones, humerus, and pelvis. The vertebrae are less frequently involved. FD of the spine mostly occurs in polyostotic form and the monostotic form is an extremely rare condition and only 13 cases with lumbar involvement have been reported until now. Investigating all these 13 cases, monostotic FD of the lumbar vertebrae can affect any level and both the gender $[9,10]$.

The most common symptom that patients present with is pain however, there are also reports of deformity, radiculopathy, myelopathy and even paralysis. Moreover, incidental or posttraumatic finding was reported in many of the cases [8].

Regarding of planning for the treatment, there is not an invariant approach and most of the surgeons prefer to decide per case. In most of the case reported, aggressive curettage of the bone replaced with allograft was the treatment of the choice [11-13]. There was always a fear about recurrence or malignant transformation. Long term follow ups show only few transformation of monostotic FD to osteogenic sarcoma and in some cases there is residual fibrous tissue left which invades to the grafts [14-17]. Nevertheless, in all cases, regardless of the method of choice for treatment, there were mostly good outcomes. In this case we presented a pathologic fracture of monostotic FD of L3 vertebra which was treated with curettage and fixation with cage, screw and allograft insertion with 1 year of good follow-up.

\section{References}

1. Ippolito E, Bray EW, Corsi A, De Maio F, Exner UG, et al. (2003) Natural history and treatment of fibrous dysplasia of bone: a multicenter clinicopathologic study promoted by the European Pediatric Orthopaedic Society. J Pediatr Orthop B. 12: $155-177$.

2. DiCaprio MR, Enneking WF (2005) Fibrous dysplasia. Pathophysiology evaluation, and treatment. J Bone Joint Surg Am 87: 1848-1864.

3. Weinstein LS (2006) G(s)alpha mutations in fibrous dysplasia and McCuneAlbright syndrome. J Bone Miner Res 21: 120-124.

4. Kuznetsov SA, Cherman N, Riminucci M, Collins MT, Robey PG, et al. (2008) Age-dependent demise of GNAS-mutated skeletal stem cells and "normalization" of fibrous dysplasia of bone. J Bone Miner Res 23: 1731-1740.

5. Schwindinger WF, Francomano CA, Levine MA (1992) Identification of a mutation in the gene encoding the alpha subunit of the stimulatory $G$ protein of adenylyl cyclase in McCune-Albright syndrome. Proc Natl Acad Sci USA 89: 5152-5156.

6. Gorham LW, Campbell EH, Howard WC, Donhauser JL, Rust NH (1941) Albright's Syndrome-A Group of Cases Characterized by Osteitis Fibrosa Disseminata, Areas of Pigmentation and a Gonadal Dysfunction. Trans Am Clin Climatol Assoc 57: 179-187.

7. Harris WH, Dudley HR Jr, Barry RJ (1962) The natural history of fibrous dysplasia. An orthopaedic, pathological, and roentgenographic study. J Bone Joint Surg Am 44: 207-233.

8. Meredith DS, Healey JH (2011) Twenty-year follow-up of monostotic fibrous dysplasia of the second cervical vertebra: a case report and review of the literature. J Bone Joint Surg Am 93: 74

9. Arantes M Vaz AR, Honavar M, Resende M, Pereira JR (2008) Fibrous dysplasia of the first cervical vertebra. Spine 33: 933-935.

10. Proschek D, Orler R, Stauffer E, Heini $P$ (2007) Monostotic fibrous dysplasia of the spine: report of a case involving a cervical vertebra. Arch Orthop Trauma Surg 127: 75-79.

11. Mezzadri JJ, Acotto CG, Mautalen C, Basso A (1999) Surgical treatment of cervical spine fibrous dysplasia: technical case report and review. Neurosurgery 44: $1342-1346$ 
Citation: Habibollahzadeh P, Sadat M, Mehrpour SR, Hassanmirzaei B, Mozafari M (2013) Monostotic Fibrous Dysplasia of the Lumbar Spine with Pathologic Fracture: A Case Report with Treatment and Follow-up. J Spine 2: 140. doi:10.4172/2165-7939.1000140

12. Demiralp B, Ozturk C, Ozturan K, Sanisoglu YS, Cicek IE, et al. (2008) Prophylactic intramedullary nailing in monostotic fibrous dysplasia. Acta Orthop Belg 74: 386-390.

13. Schoenfeld AJ, Koplin SA, Garcia R, Hornicek FJ, Mankin HJ, et al. (2010) Monostotic fibrous dysplasia of the spine: a report of seven cases. J Bone Joint Surg Am 92: 984-988.

14. Kim GT, Lee JK, Choi BJ, Kim J, Han SH, et al. (2010) Malignant transformation of monostotic fibrous dysplasia in the mandible. J Craniofac Surg. 21: 601-603.
15. Rodenberg J, Jensen OM, Keller J, Nielsen OS, Bünger C, et al. (1996) Fibrous dysplasia of the spine, costae and hemipelvis with sarcomatous transformation. Skeletal Radiol 25: 682-684.

16. Yalniz E, Er T, Ozyilmaz F (1995) Fibrous dysplasia of the spine with sarcomatous transformation: a case report and review of the literature. Eur Spine J 4: 372-374.

17. Huvos AG, Higinbotham NL, Miller TR (1972) Bone sarcomas arising in fibrous dysplasia. J Bone Joint Surg Am 54: 1047-1056. 